\title{
Evidence-Based Digital Tools for Weight Loss Maintenance: The NoHoW Project
}

\author{
R. James Stubbs ${ }^{a}$ Cristiana Duarte ${ }^{a, h}$ António L. Palmeira ${ }^{b}$ Falko F. Sniehotta ${ }^{c}$ \\ Graham Horgan $^{d}$ Sofus C. Larsen ${ }^{f}$ Marta M. Marques ${ }^{g}$ Elizabeth H. Evans ${ }^{c}$ Miikka Ermes ${ }^{e}$ \\ Marja Harjumaa ${ }^{\mathrm{e}}$ Jake Turicchi ${ }^{\mathrm{a}}$ Ruari O'Driscoll ${ }^{\mathrm{a}}$ Sarah E. Scott $^{\mathrm{a}}$ Beth Pearson $^{\mathrm{a}}$ \\ Lauren Ramsey $^{\mathrm{a}}$ Elina Mattila ${ }^{\mathrm{e}}$ Marcela Matos $^{\mathrm{h}}$ Paul Sacher $^{\mathrm{l}}$ Euan Woodward $^{\mathrm{m}}$ \\ Marie-Louise Mikkelsen ${ }^{f} \quad$ Kirby Sainsbury $^{c}$ Inês Santos ${ }^{b, n} \quad$ Jorge Encantado $^{b} \quad$ Carol Stalker $^{i}$ \\ Pedro J. Teixeirab Berit Lilienthal Heitmann ${ }^{f, j, k}$

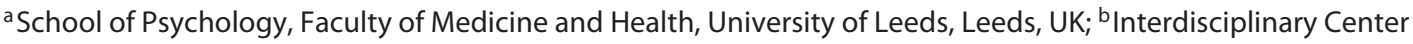 \\ for the Study of Human Performance (CIPER), Faculdade de Motricidade Humana, Universidade de Lisboa, Lisbon, \\ Portugal; ' Population Health Sciences Institute, Faculty of Medical Sciences, Newcastle University, Newcastle, UK;

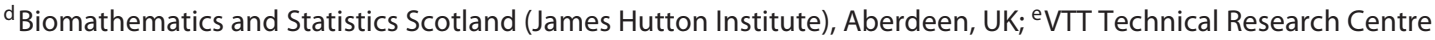 \\ of Finland, Espoo, Finland; ${ }^{f}$ Research Unit for Dietary Studies, The Parker Institute, Bispebjerg and Frederiksberg \\ Hospital, Frederiksberg, Denmark; 9Trinity Centre for Practice and Healthcare Innovation and ADAPT Centre, Trinity \\ College Dublin, Dublin, Ireland; ${ }^{h}$ Center for Research in Neuropsychology and Cognitive and Behavioral Intervention, \\ University of Coimbra, Coimbra, Portugal; i College of Life and Natural Sciences, University of Derby, Derby, UK; \\ jThe Boden Institute of Obesity, Nutrition, Exercise and Eating Disorders, The University of Sydney, Sydney, NSW,

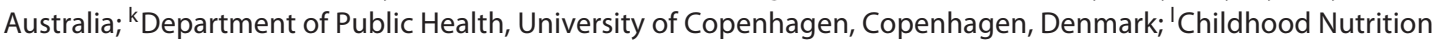 \\ Research Centre, University College London, London, UK; ${ }^{\mathrm{m}}$ European Association for the Study of Obesity, \\ Teddington, UK; ${ }^{n}$ Laboratório de Nutrição, Faculdade de Medicina, Universidade de Lisboa, Lisboa, Portugal
}

\section{Keywords}

Emotion regulation $\cdot$ Information and communication technologies · Motivation · Obesity · Self-regulation · Weight loss maintenance

\begin{abstract}
Background: Effective interventions and commercial programmes for weight loss (WL) are widely available, but most people regain weight. Few effective WL maintenance (WLM) solutions exist. The most promising evidence-based behaviour change techniques for WLM are self-monitoring, goal setting, action planning and control, building self-efficacy, and techniques that promote autonomous motivation (e.g., provide choice). Stress management and emotion regulation techniques show potential for prevention of relapse and
\end{abstract}

karger@karger.com www.karger.com/ofa

Karger $\stackrel{\text { ' }}{5}$

GOPEN ACCESS
(C) 2021 The Author(s)

Published by S. Karger AG, Basel

This is an Open Access article licensed under the Creative Commons Attribution-NonCommercial-4.0 International License (CC BY-NC) (http://www.karger.com/Services/OpenAccessLicense), applicable to the online version of the article only. Usage and distribution for commercial purposes requires written permission. weight regain. Digital technologies (including networkedwireless tracking technologies, online tools and smartphone apps, multimedia resources, and internet-based support) offer attractive tools for teaching and supporting long-term behaviour change techniques. However, many digital offerings for weight management tend not to include evidencebased content and the evidence base is still limited. The Project: First, the project examined why, when, and how many European citizens make WL and WLM attempts and how successful they are. Second, the project employed the most up-to-date behavioural science research to develop a digital toolkit for WLM based on 2 key conditions, i.e., selfmanagement (self-regulation and motivation) of behaviour

The work should be attributed to the School of Psychology, Faculty of Medicine and Health, University of Leeds, Leeds, UK. 
and self-management of emotional responses for WLM. Then, the NoHoW trial tested the efficacy of this digital toolkit in adults who achieved clinically significant $(\geq 5 \%) \mathrm{WL}$ in the previous 12 months (initial BMI $\geq 25$ ). The primary outcome was change in weight $(\mathrm{kg})$ at 12 months from baseline. Secondary outcomes included biological, psychological, and behavioural moderators and mediators of long-term energy balance (EB) behaviours, and user experience, acceptability, and cost-effectiveness. Impact: The project will directly feed results from studies on European consumer behaviour, design and evaluation of digital toolkits selfmanagement of EB behaviours into development of new products and services for WLM and digital health. The project has developed a framework and digital architecture for interventions in the context of EB tracking and will generate results that will help inform the next generation of personalised interventions for effective self-management of weight and health.

(c) 2021 The Author(s)

Published by S. Karger AG, Basel

\section{Introduction}

Overweight/obesity is one of the greatest societal challenges to the health and wellbeing of European citizens, affecting more than half of the adult population [1]. Obesity prevalence accounts for $3-8 \%$ of health costs and 10 $13 \%$ of deaths in different parts of the region [2]. The overall cost of obesity could be as high as EUR 118-236 billion, because obesity is linked to a range of physical and psychological illnesses [3]. These costs are set to rise in parallel with obesity prevalence [4]. Obesity affects psychological wellbeing, self-esteem, education and employment prospects especially in younger people and women $[5,6]$. It is associated with decreases in health-related quality of life and overall life expectancy and greater health care expenditures [7]. The projected health care costs for obesity's co-morbid conditions such as diabetes are set to escalate in the next few decades, placing potentially unsustainable burdens on health care systems [8].

Complex conditions such as obesity that have a large behavioural component to their development and maintenance do not have simple solutions but require concerted action through multicomponent interventions aimed at both prevention and treatment. Evidence-based interventions and commercial programmes for weight loss (WL) are widely available $[9,10]$. Evidence from large samples in the USA, Europe, and globally suggests that approximately $42 \%$ of adults report trying to lose weight and $23 \%$ of adults report trying to maintain weight annually [11].
Eighty percent of those who achieve clinically significant WL fail to sustain that WL over a period of 12 months [12]. Factors responsible for weight regain include physiological resistance to WL [13], the obesogenic environment [8], individual experiences of stress and life events [14], and a general lack of knowledge on the part of consumers on how to effectively manage energy balance (EB) behaviours (dietary intake and physical activity) [15].

There is now considerable evidence documenting the effects of both non-commercial and commercial behavioural, pharmacological, or surgical interventions on initial WL $[9,10,16-28]$. Diet and lifestyle interventions produce mean WL of $<5 \mathrm{~kg}$ after $2-4$ years, pharmacological therapies produce mean WL of 5-10 kg over 1-2 years, and surgery tends to yield mean WL of $25-75 \mathrm{~kg}$ after 2-4 years [29]. All of these approaches are subject to some degree of longer-term weight regain $[17,30]$. Behavioural programmes have central elements of dietary energy restriction, some form of behavioural counselling and support, and some advice regarding physical activity (see below) [31, 32]. For completers of nonsurgical WL clinical trials (i.e., energy-restricted diets, diet plus exercise, meal replacements, a very low-calorie diet, or Orlistat) mean WL of 5-9\% occur, plateau at 6-12 months, and gradually creep upwards between 24 and 48 months (where data is available) [17].

Behaviour change interventions, some available commercially, deliver an initial WL [33-37]. However, longterm WL maintenance (WLM) is more challenging; weight relapse is common [17] and obesity is a chronic relapsing condition $[38,39]$. National weight control registries have shown that WLM is possible for thousands of individuals previously diagnosed with obesity, but not probable for most [12, 40, 41]. Several systematic reviews and analyses have identified the critical elements that future interventions must effectively address and described modest effect sizes that need to be amplified to improve longer-term weight outcomes. These include behavioural interventions to change diet, physical activity, and other weight control behaviours through components targeting self-regulation of behaviours, increased autonomous motivation, and self-efficacy [42-45].

\section{Energy Balance-Related Behaviours and Longer- Term Weight Management}

Knowledge has accumulated in recent years regarding the most consistent predictors/mediators of sustained change in EB behaviours, which illustrate the potential to 
advance the state of the art in improving obesity management at the individual level. There is evidence that some of the behaviours that lead to WL are continued during WLM and that some additional behaviours are recruited during the period of WLM [46]. The transition from WL to WLM is a dynamic interaction between behavioural strategies to lose weight and the physiological (and environmental) resistance to WL $[8,19,47]$, which creates a tonic pull that can undermine the behaviours that led to the initial WL. Thus, those who lose weight are at a high risk for weight regain. Many people who have engaged in an initial WL attempt actually aim to achieve further WL rather than WLM. Many people attempting to maintain their WL therefore experience periods where they revisit strategies they originally used to lose weight, to cope with weight relapse, or to lose further weight.

Longer-term weight management typically involves attempts at achieving sustainable change in habitual eating, activity, and self-regulation behaviours. These changes interact with changes in physiological and emotional systems, which together with aspects of the environment (food marketing, psychosocial stress, work routines, time urgency, and sedentary routines) produce strong influences that promote weight relapse. Thus, there is a need to develop sustainable solutions that prevent weight relapse $[38,48]$.

\section{Mechanisms of Action in Behaviour Change Interventions for Longer-Term Weight Management}

WL trajectories slow as time progresses. The exact physiological mechanisms that oppose further WL and often promote weight regain are multiple, complex, individually subtle, and difficult to quantify specifically, although they include changes in energy expenditure, appetite, and energy intake [49-54]. In addition, many people experience behavioural lapses and relapses as more pronounced situational or momentary events. Avoiding both gradual and more pronounced weight regain requires behavioural strategies in which relapse coping and WLM become learned skills of self-regulation, autonomy and motivation [55-59] as part of a longer-term process [38, 60-62]. Evidence suggests that core features of more effective WLM interventions include behaviour change techniques such as self-monitoring (of weight and behaviour), relapse prevention, goal setting, and action plans for diet and physical activity, which improve self-efficacy $[44,58,63]$. Thus, self-regulation of EB behaviours appears to be a key intervention target for longer-term weight management. Physical activity and dietary interventions based on current behaviour change theories characteristically achieve relatively modest effects of over 12 months [64, 65].

Research identifying and linking specific behaviour change approaches or techniques to mechanisms of action of behaviour change interventions is still a developing field $[66,67]$. Historically, behaviour change models have focused on social cognition (e.g., beliefs, intentions, attitudes, and decisions), emphasising pathways of reasoned action in which pre-decisional motivation leads to the formation and implementation of intentions as volitional action $[68,69]$. It is also believed that automatic processes (emotions, desires, habits resulting from associative learning and physiological states) may also have a large impact on behaviour and behaviour change. These processes tend to be relatively rapid, automatic, impulsive (less conscious), and habitual in comparison to the slow, deliberative processes of motivation and self-regulation $[70,71]$. Furthermore, in the context of EB behaviours, the development of self-regulatory behaviour change is sometimes effortful, particularly in the face of a physiological resistance to WL, while unconscious or automatic components of EB behaviours are rapid and effortless [72]. Such processes may have a considerable capacity to undermine the initial self-regulation of EB behaviours (particularly eating behaviours) in the face of a physiological system that resists longer-term WL. Automatic components of self-regulation may also promote longer-term behaviour changes if they are engaged and developed [72-74].

At the outset of the project, we hypothesised that another aspect of automaticity potentially affecting EB behaviours is distress tolerance and emotional responses. Food is a powerful source of pleasure and reward [75-78]. This has consequences for our ability to form planned, reasoned behavioural pathways to manage our weight. People with overweight and obesity commonly experience stigma, which enhances psychosocial stress and negatively impacts physical and mental wellbeing [79-81]. Stigma impacts shame, self-criticism, and unfavourable social comparisons, creating feelings of inferiority and inadequacy in relation to others [82]. Weight management therefore has a large emotional dimension. The relationship between stress, emotion, and food intake can derail strategies of planned behaviour and promote relapse [83, 84]. This is probably why shame and self-criticism are associated with binge eating [85], obesity [79, 80], and problems linked to body image $[82,86,87]$. Acceptance, self-compassion, and mindfulness-based approaches 


\section{Behavioural and psychological predictors of weight loss and regain}
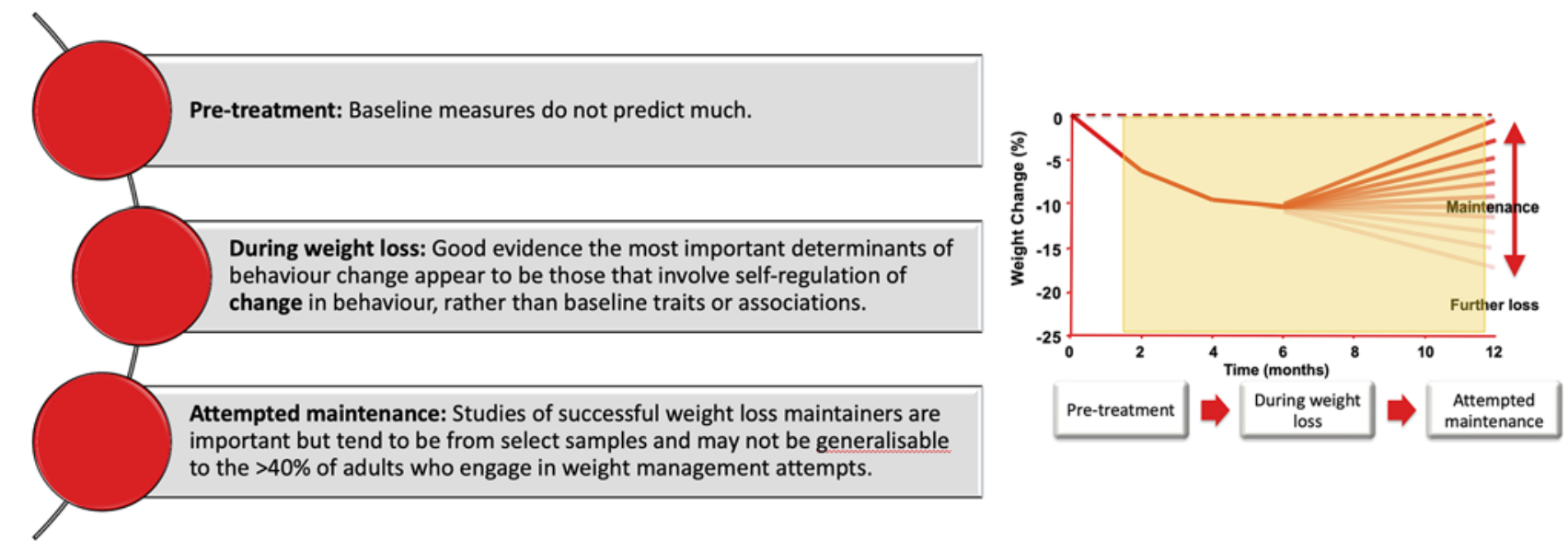

Fig. 1. The majority of studies examining psychosocial predictors of longer-term weight outcomes, as mechanisms of action of behaviour change interventions, have used either pre-treatment predictors $[98,99]$ or correlates of WL and maintenance rather than sequential measures of outcomes throughout intervention and follow-up periods. Recent evidence suggests that factors influencing

may help to address these issues [88] and may help to reduce obesity-related eating behaviours $[89,90]$. At the outset of the project we hypothesised that self-monitoring, self-regulation, and autonomous motivation in WLM could favourably be supported by strategies that promote stress management and emotion regulation [88, 91-97].

It is important to note that the majority of studies examining psychological and social predictors of longerterm weight outcomes as mechanisms of action of behaviour change interventions have either used pre-treatment predictors $[98,99]$ or correlates of WL and maintenance rather than sequential measures of outcomes throughout intervention and follow-up periods (Fig. 1). To our knowledge, no studies have directly linked longitudinal changes in compensatory EB physiology and behaviour to mechanisms of action of behaviour change interventions. The current scientific debate focuses on the process of WLM given that pre-treatment predictors of WL tend to explain relatively little of subsequent weight outcomes [44, 98, 99]. For instance, Varkevisser et al. [44] found that aspects of self-regulation of eating, activity, and weight control behaviours are effective for WLM through changes in behaviours during the course of weight management interventions are important determinants of success of failure at longer-term weight management [44]. It therefore appears (albeit from limited evidence) that it is important to understand processes of change in the self-management of EB behaviours during the course of weight management interventions.

their impact on change in behaviour during weight management attempts. It therefore appears (albeit from limited evidence) that it is important to understand processes of change in the self-management of EB behaviours during the course of weight management interventions. This requires longitudinal studies where processes of psychosocial change and EB behaviours are both tracked over time.

\section{Digital Approaches to Weight Management Interventions}

There are currently numerous WL mobile applications (apps) available to citizens. Initial opportunistic reviews of the effectiveness of commonly available WL mobile apps available on Apple and Android websites in 2013 showed that they typically included only a minority of the behavioural strategies shown to be effective in evidencebased interventions $[100,101]$. In particular, behavioural strategies that help to improve motivation, reduce stress, and improve problem solving were generally missing in 
such apps [101]. A systematic review of weight management apps suggested that alone they produce modest effects on weight and health outcomes and they may be more effective as part of multicomponent interventions [102]. This suggests that most weight management apps previously missed key evidence-based approaches for longer-term behaviour changes. A systematic review and meta-analysis of e-health interventions for the prevention and treatment of obesity found evidence of significant but modest effects of eHealth interventions as a treatment option for obesity, but there was insufficient evidence to suggest that such interventions may be valuable for WLM [103]. A more recent extensive systematic review and meta-analysis assessing the effectiveness of app-based mobile interventions for improving nutritional behaviours and health outcomes found some beneficial effects of goals and planning, feedback and monitoring, shaping knowledge, and social support on both of these outcomes [104]. Other systematic reviews indicate that weight management apps may have positive effects on weight-related outcomes, although the methodological quality of many studies is low $[105,106]$. While there is an urgent need for sustainable and cost-effective solutions that are easy and convenient to use for the consumer and manageable for the health care provider, it is important to conduct randomised trials of digital technologies for WLM and to try to understand the mechanisms by which they may influence weight and health outcomes.

\section{The NoHoW Project}

The NoHoW project was a 5-year European Commission Horizon 2020-funded Research and Innovation Action in the Personalising Health and Care-Self Management of Health and Disease: citizen engagement and mHealth call, focused on developing evidence-based digital technologies and tools for WLM (grant agreement No. 643309; Fig. 2). The project was developed around the most promising evidence-based behaviour change techniques for WLM (self-monitoring, goal setting, action control, autonomous motivation, and also assessment of building self-efficacy) combined with contextual behavioural science approaches to emotion regulation and stress management to facilitate weight-regain prevention. Evidence of effective weight management practices is still limited. To design a digital offering that addresses the needs of European citizens, the project initially examined why a representative sample of European citizens make WL efforts, how often these efforts are

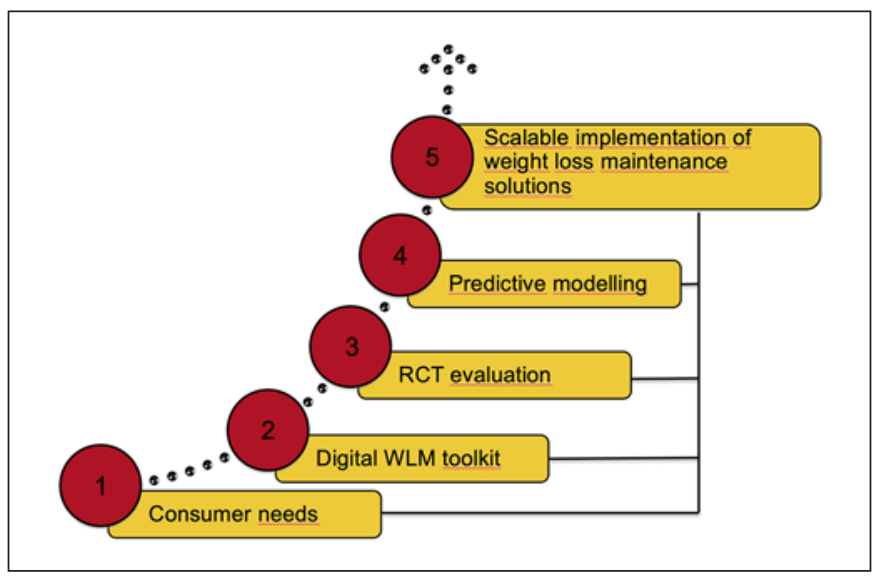

Fig. 2. The primary objectives of the NoHoW project were to understand how weight is lost and managed in Europe, develop a digital TK to support WL maintenance, evaluate the impact of the TK on WL maintenance through a $2 \times 2$ factorial randomised controlled trial, identify predictive signatures of weight relapse and maintenance, and inform future digital interventions for longerterm weight management.

made over a year, and the specific methods people use for $\mathrm{WL}$. Information was gained from international surveys of 2,000 consumers in 3 countries, from longitudinal analysis of weight management experience in an existing cohort of 2,000 successful WL maintainers, and from qualitative studies of those engaged in WLM attempts [107]. Because information technology offers cost-effective, scalable, and attractive tools for teaching and supporting these techniques, some of which are currently delivered through resource-intensive face-to-face therapies, the project has developed a digital toolkit (TK) using theoretically informed, evidence-based behaviour change approaches. The project has surveyed digital interventions for WLM in the context of the most up-to-date behavioural science research, using this knowledge to develop a digital TK for WLM based on 2 key conditions, i.e., self-management of behaviour and self-management of emotional responses for WLM. The project targeted adults who have achieved clinically significant $(\geq 5 \%) \mathrm{WL}$ in the previous 12 months (initial BMI $\geq 25$ ). It formally tested the efficacy of this digital TK through a large-scale randomised controlled trial, conducted over a 6-month active intervention and subsequent 12-month follow-up, by using a mobile enabled website, activity trackers, and $\mathrm{Wi}$-Fi weight scales. The primary outcome was change in weight $(\mathrm{kg})$ at 12 months from baseline. Secondary outcomes were 12-month changes in body composition (e.g., bio-impedance analysis), health biomarkers (HbA1c, lip- 


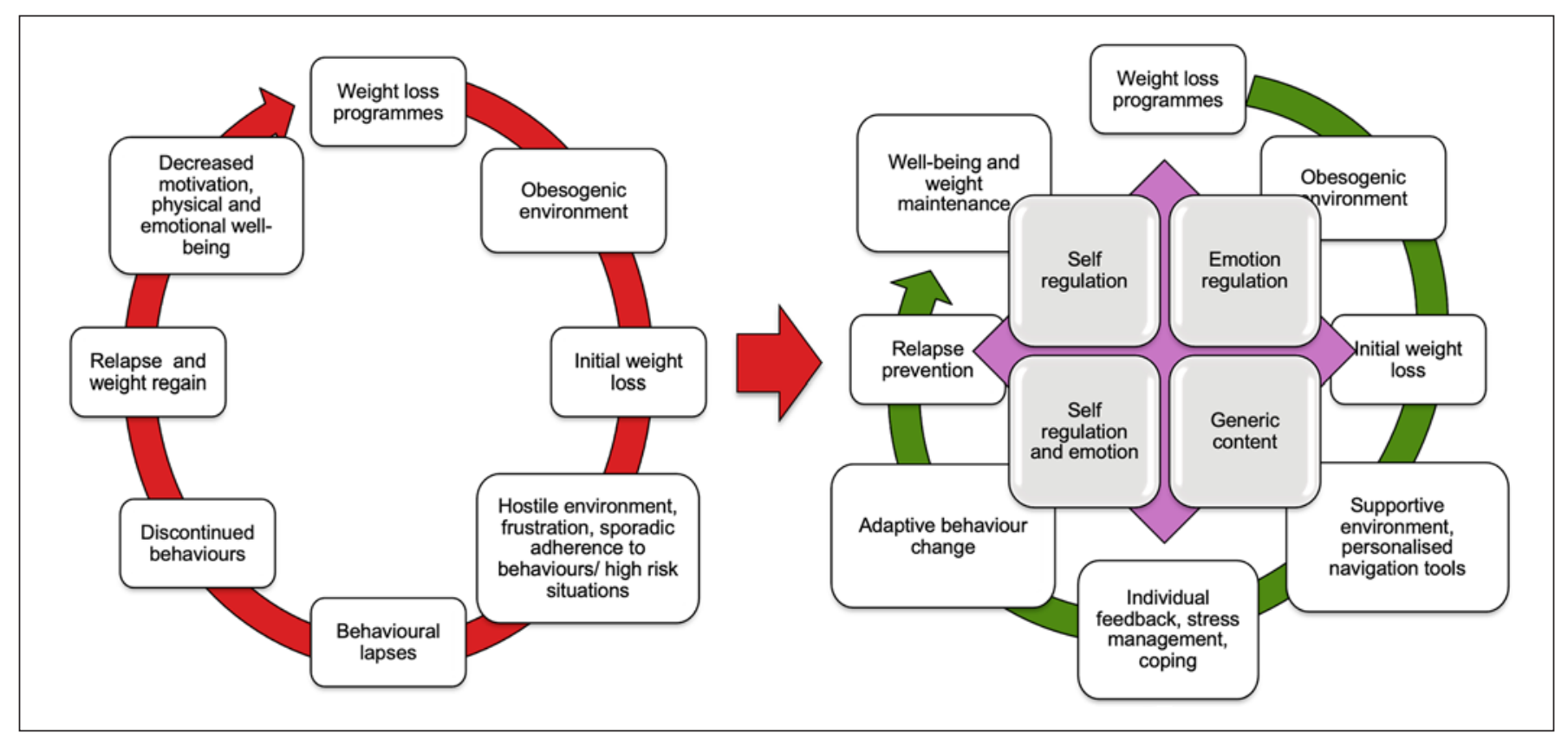

Fig. 3. Conceptual basis for the development of the NoHoW TK and its intended impact on the cycle of WL and weight regain.

ids, blood pressure, and hair cortisol), dietary intake, physical activity, sleep, stress, and motivational, self-regulatory, emotion-regulatory moderators/mediators of WLM, as well as user engagement and experience and the acceptability and cost-effectiveness of the intervention. State-of-the-art consumer devices were employed to track physical activity and body weight throughout the trial. Finally, we developed a digital architecture that linked the TK to users, collected and streamed data from participants to a central data hub for storage and analysis, and facilitated trial administration and management. The overall project was based around 5 objectives.

\section{Objective 1: To Understand How Weight Is Lost and Managed in Europe}

To engage citizens in longer-term weight management, and design evidence-based tools to support them, we characterised weight management practices across Europe. This has established when and how a representative sample of 2,000 Europeans make WL efforts over a year $[14,107]$. We also followed an existing cohort of 2,000 successful WL maintainers in a commercial weight management programme longitudinally over 12 months to identify the factors that contribute to successful WLM and collected qualitative insights into self-regulatory behaviours in WLM. In other fields of prevention science, such as smoking cessation, the answers to these questions are known and have contributed to progress in self-management and improved health [108]. The project aimed to fill this gap for obesity, WL, and WLM.

\section{Objective 2: To Develop an ICT-Enabled Toolkit to}

Support Weight Loss Maintenance

We have developed a digital TK of behaviour change tools to support users in maintaining their WL (Fig. 3). These tools cover: (1) self-regulation and motivational skills to promote volitional aspects of WLM and (2) emotion regulation and stress management to improve eating control. The techniques in each condition were implemented as a "menu" or portfolio of ICT-enabled tools (tracking devices, mobile phone applications [apps], websites, and multimedia resources). Within each condition, participants were reminded to visit the TK to complete sessions and could, to a limited extent, choose the sequence and number of times they accessed TK components. Participants were asked to wear the tracking devices (Fitbit Charge 2) continuously (except during charging and water-based activities) and weigh themselves twice a week (Fitbit Aria cloud-connected scales). The digital TK was linked to a central data hub, which: (1) aggregated data from all the measures made on each user; (2) supported limited tracking, feedback, and behavioural 


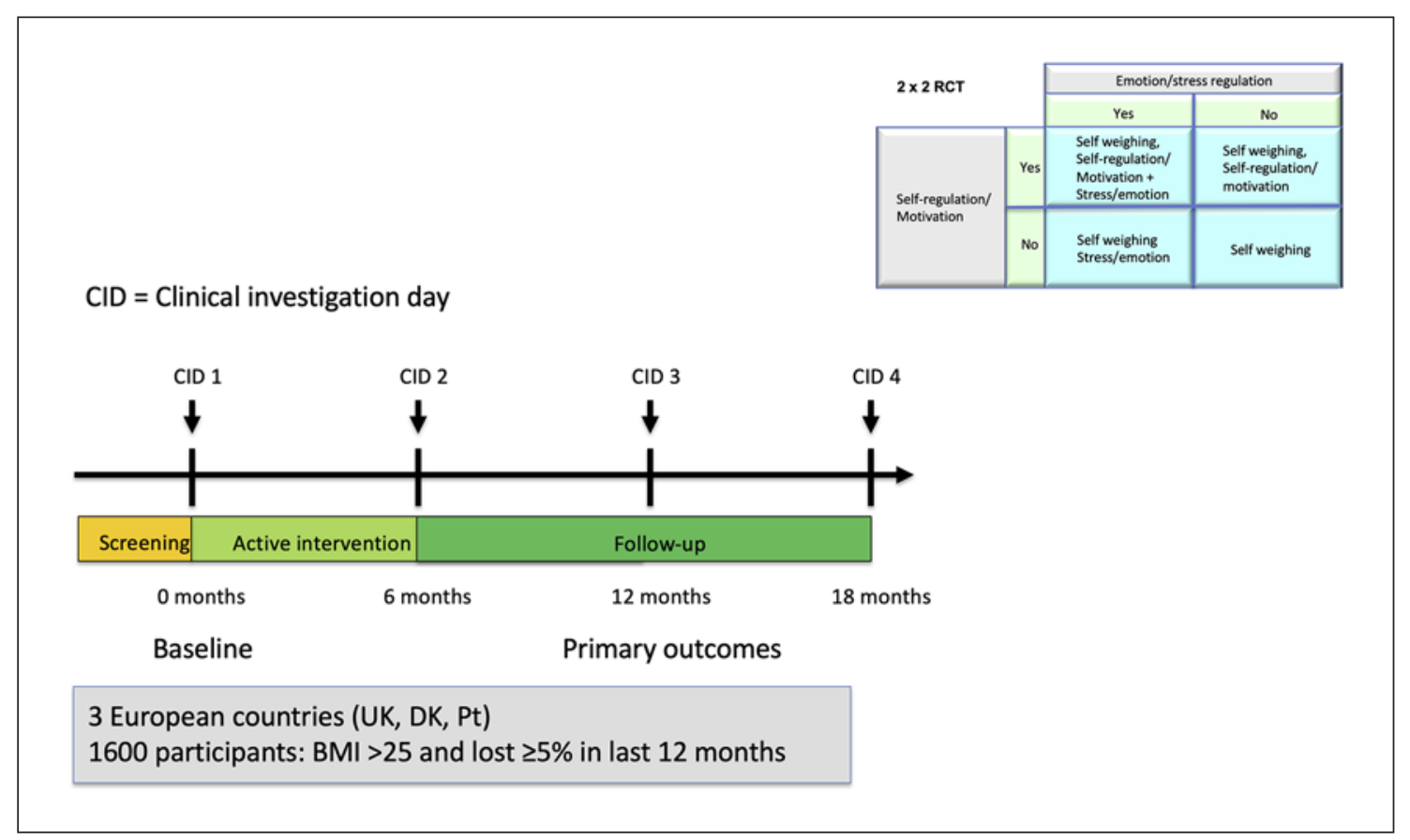

Fig. 4. Design of the NoHoW trial, a $2 \times 2$ factorial randomised controlled intervention (arm 1: self-regulation, and arm 2: emotion regulation and stress management, self-regulation plus emotion regulation/stress management, and active control) in 1,627 obese adults to identify moderators and mediators of behavioural self-regulation.

signature profiling; and (3) provided statistical models and analyses of the intervention outcomes. User evaluation of the TK was measured through a user-centred design approach [109-111].

\section{Objective 3: To Evaluate the Impact of the NoHoW}

Toolkit on Weight Loss Maintenance

Through a $2 \times 2$ factorial randomised controlled intervention (arm 1: active control, arm 2: self-regulation + motivation, arm 3: emotion regulation, and arm 4: selfregulation plus emotion regulation) in 1,627 adults with overweight and/or obesity who successfully lost $>5 \%$ weight in the past 1 year, moderators and mediators of weight outcomes will be identified [112] (Fig. 4). The efficacy and cost-effectiveness of the TK and multiple mediation analyses of processes of behaviour change will be reported in separate publications.

\section{Objective 4: To Identify Predictive Signatures of \\ Weight Relapse and Maintenance}

Through statistical analysis and modelling of primary and secondary outcome data in the data hub, we will relate psychological and behavioural outcomes to tracked
EB behaviours [113], sleep [114], and weight change. This will establish a foundation for future predictive decision support systems that match user profiles to TK development strategies for WLM.

Objective 5: Inform Future Digital Interventions for Longer-Term Weight Management

We will use information gathered from the consumer experience/needs analysis, from the TK development, and from the RCT to inform future design of hardware and software solutions for health behaviour change in primary care and commercial settings.

\section{Overall Approach and Methodology}

The project began with work package 1 (WP1), where we established how weight is lost and managed in European citizens through a pan-European survey of 2,000 consumers to establish why, when, and how many European citizens make WL efforts over a year, how often these efforts are made, and the specific methods people use. We also established how WL successes and weight 


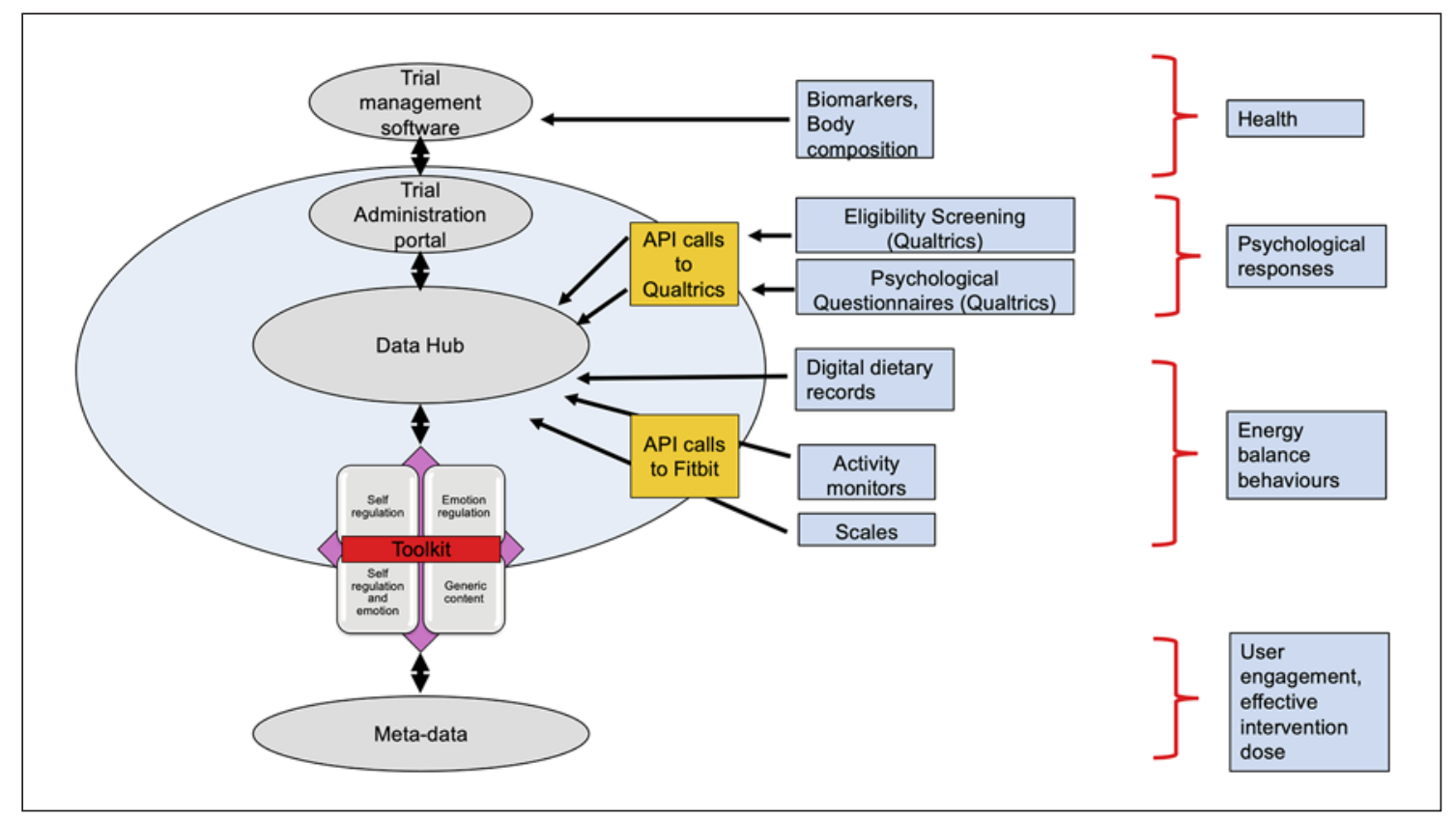

Fig. 5. Schematic diagram of the overall digital architecture of the NoHoW project.

relapses relate to socioeconomic, cultural, and specific lifestyle contexts. We determined how many of these efforts are successful as defined by a WL of $\geq 5 \%$ sustained for at least 12 months. These data informed the design of the digital TK for weight management [14, 107].

We have also conducted 12-month repeat longitudinal measures of weight management experience in an existing cohort of 2,000 successful WL maintainers attending Slimming World ${ }^{\mathrm{TM}}$. The infrastructure to identify these participants and regularly follow-up their weight was established through the regular data monitoring architecture of Slimming World ${ }^{\mathrm{TM}}$ [115]. Finally, we explored self-regulation of food intake in Danish WL maintainers and the potential of NoHoW to attract user groups through qualitative research methods [116].

In WP2 we developed and validated the NoHoW TK and its specific components (Fig. 3). WP2 has been informed by: (1) user needs and requirements from WP1, (2) knowledge from behaviour change theory and known applications, (3) research evidence on predictors of WLM, and (4) previous experience from project partners in designing health-related ICT-based tools, for example [117]. This WP added self-tracking technologies (FitBit Charge 2 and Aria scales) for continuous tracking of physical activity and body weight. Throughout the trial the University of Leeds has been working on relating these measures to criterion measures of energy expendi- ture and storage through complex mathematical modelling [118]. Interactive tools were created for delivering the intervention content on self-regulation/motivational aspects of WLM and emotion regulation based on logic models derived using evidence from recent systematic reviews [42, 43, 119-121]. The full description of the TK will be given in a separate publication.

In WP3 and WP4 we delivered an RCT to evaluate the efficacy and cost-effectiveness of the TK (Fig. 4). The full protocol for the trial is described in a separate publication [112]. WP3 developed the protocol for the NoHoW trial and: (1) finalised trial design, management, study population and sample size (inclusion/exclusion criteria), recruitment strategy, randomisation, outcome measurement, and process evaluation; (2) harmonised intervention components, measures, and data export at the 3 centres; and (3) piloted standard operating procedures for all intervention components, measures, and data export at the 3 intervention centres. The RCT was a 4 -arm, $2 \times 2$ factorial intervention designed to evaluate the efficacy and cost-effectiveness of the NoHoW Platform on WLM in 1,627 adults with overweight/obesity (BMI of $28-40$, aged $18-65$ years, who had lost $\geq 5 \%$ of their weight in the last 12 months) at 3 intervention centres in the UK (Leeds), Portugal (Lisbon), and Denmark (Copenhagen). The factorial structure is a major step forward from conventional 2 -armed trials. It allows tests of 3 main hypoth- 
eses, i.e., (1) effects of self-regulation intervention, (2) effect of emotional/stress regulation, and (3) potential synergic effects of delivering both together. Secondary moderation analysis will test if baseline features predict who is more likely to benefit from each of the interventions. The 4 arms of the trial enable us to examine if specific combinations of digitally delivered TK components affect WLM success over and above frequent self-monitoring. WP4 delivered the NoHoW trial at the 3 intervention centres through intervention delivery, monitoring, governance and ethics, health economics, database management, and statistical analysis. This WP was responsible for conducting the intervention and follow-up with final measures to monitor the effect of the intervention. The main results of the NoHoW intervention will be given in a separate publication.

WP5 managed the overall digital architecture of the project and created a central data storage facility whereby all data collected during the project was delivered, cleaned, and stored securely for the duration of the project and 20 years thereafter (Fig. 5). The data hub received and deposited data during the intervention and made available all data generated in the project (WP1-4 and 6). This database has been set up in Edinburgh, Scotland, with links to the TK management centre (WP2) for automated data feed in from the TK as used by participants in the intervention. At the end of the intervention, WP5 provided the primary statistical analysis of the RCT outcomes and health economics analysis to feed into WP6, the development of the business model for the NoHoW project.

WP6 was responsible for the future exploitation planning for TK v2.0, as well as for managing confidentiality/ IP and initial development of a stakeholder network focused on long-term behaviour change, relapse prevention, and WLM. Exploitation planning activities explored how to make results, insights, and technologies from NoHoW available across different channels based on their commercialisation and impact potential.

WP7 promoted, communicated, and disseminated project findings to identified target audiences (general public, researchers and other projects, clinicians, public health decision makers, and health care sector) through on-going research publications, educational and guidance/policy/health promotion materials, presentations, and podcasts.

WP8 was responsible for project management, i.e., setting goals, monitoring progress, identification of issues and solutions, and orchestrating all partners and workpackages as a coherent whole (Fig. 6). This WP acted as a

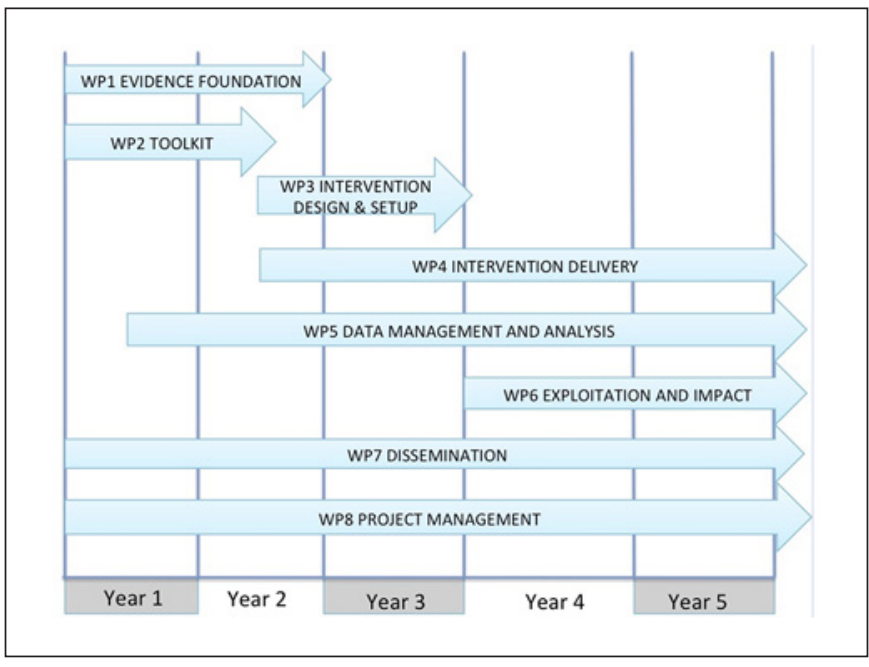

Fig. 6. Gannt chart showing the WP of the NoHoW project.

liaison with the EU, handled administration, deliverables, and reports, and addressed project-wide issues such as quality, intellectual property and intra-team communication.

\section{Advancing the State of the Art}

The NoHoW project has gathered an evidence base of weight management practices across Europe and around the world [11] and longitudinally tracked psychological predictors of WLM in a large cohort of commercial weight management participants who have achieved a significant amount of WL and are explicitly seeking to maintain that loss [14, 107].

The NoHoW TK is a research grade technology that, where possible, has used commercially available solutions (Fitbit activity and weight trackers and Qualtrics questionnaires) to improve the experience of participants engaged in its evaluation. The TK is based on: (1) evidencebased state-of-art theories of behaviour change, including techniques associated with self-regulation skills (self-regulation theory), building autonomous motivation (selfdetermination theory), and emotional regulation and stress management, and (2) web design expertise and (3) user testing. Informed by the guidelines for the development of complex behaviour change interventions and principles applied in previous theory-based behaviour change interventions, we have used systematic approaches to the translation of theory and evidence from face-toface interventions to digital intervention components. 
This included: (1) theory selection and development of the content logic models, (2) TK guiding principles and selection of the intervention techniques, (3) translating these techniques into the TK components, (4) TK technical development, and (5) user evaluation and TK refinement. The NoHoW TK was hypothesised to influence mechanisms of action that may impact EB behaviours and longer-term weight outcomes. We have developed personalised feedback equations that, based on individual weight changes and activity behaviour (measured by the Fitbit devices), informed participants about what seemed to have worked for their individual weight journey, and we applied machine learning algorithms to predict $\mathrm{EE}$ from steps, heart rate, and subject characteristics in a range of activities, compared to indirect calorimetry [118]. These estimates of EE can be used in conjunction with (weekly) tracked body weight and the NIDDK equations for estimating changes in energy intake over time $[122,123]$.

NoHoW is the first project to develop and formally evaluate (via RCT) a digital TK combining continuous tracking of EB behaviours and body weight with theoretically informed, evidence-based digital interventions targeting self-regulation and motivation, and emotion regulation/stress management for longer-term weight management. Analyses of primary outcomes test the hypotheses that self-regulation of EB behaviours improves longer-term weight outcomes and that emotion regulation and stress management strategies help prevent weight relapse. Trial moderator analysis will determine if different psychological and behavioural profiles of participants predict the response to self-regulation or emotion-regulation interventions. Mediation analyses will determine evidence for mechanisms of action by which motivation and self-regulation and stress and emotion regulation-based behaviour change approaches may affect EB behaviours, weight, and health. User experience and tracking of user engagement with the intervention will provide data on the acceptability of digital interventions for longer-term weight management. Secondary analyses will inform more personalised digital interventions that better match intervention content and delivery to individual user needs, potentially helping to improve user engagement and the health and wellbeing of participants. The NoHoW digital architecture tracks user engagement with the intervention and relates this via the intervention logic models to moderators and mediators of any intervention effects. These behaviour change models will be evaluated in the context of objectively tracked EB behaviours. These approaches, in combina- tion, will help to inform next-generation weight management interventions in which intervention content and delivery can be better adjusted to the needs of specific individuals.

\section{Expected Impacts}

Management and maintenance of WL are difficult and rely heavily on supporting long-term individual engagement in behaviour change interventions for weight management [40], which are subject to relapse. Digital technologies, especially the use of mobile devices and online tools [124], may have the potential to enhance initial weight control attempts and facilitate self-management. NoHoW has evaluated the potential of evidence-based digital behaviour change approaches to longer-term weight management and identified important limitations to such approaches. This information is needed to develop the next generation of personalised behaviour change solutions for self-management of weight and health.

The co-design of the NoHoW TK has been informed by user engagement and experience-centred design approaches $[110,111]$ that will help to evaluate the strengths and limitations of the NoHoW TK. This is critical in developing new tools that facilitate personalised behavioural approaches to WLM and inform future interventions where individuals become co-managers of their own weight, health, and wellbeing.

The NoHoW project has enhanced our understanding of the strengths and limitations of digital approaches to weight management. The design of the NoHoW TK logic models and tracking of EB behaviours will improve our understanding of the mechanisms by which WL facilitates subsequent weight regain as a context in which behaviour change interventions attempt to operate. It is important for the research community to take stock of the reasons why promising theories for behaviour change interventions for WLM do not produce much beyond modest effects. There is a great deal to learn about why such interventions do not yet work as well as we hope they would. Considerable insight could be gained from detailed structured analyses of why WLM interventions do not work at the experiential rather than theoretical level. This will enable us to articulate the tension between selfregulation of EB behaviours and the factors that undermine it $[19,47]$. Only by clearly delineating the pathways and mechanisms of probabilistic failure will we be able to better understand how to make people more successful at longer-term WLM. 


\section{Acknowledgement}

We are grateful to Slimming World for assistance with recruitment for studies in WP1 and WP3 and for working with the consortium in developing and piloting aspects of the TK.

\section{Conflict of Interest Statement}

R.J.S. consults for Slimming World through Consulting Leeds, which is a wholly owned subsidiary of the University of Leeds. M.M.M. has provided consultancy services for Slimming World.

\section{Funding Sources}

The NoHoW project has received funding from the European Union Horizon 2020 research and innovation programme under grant agreement No. 643309. The Parker Institute, Bispebjerg and Frederiksberg Hospital, is supported by a core grant from the Oak Foundation (grant agreement No. OCAY-18-774-OFIL).

\section{Author Contributions}

R.J.S., B.L.H., P.J.T., F.F.S., A.L.P., and G.H. conceived the NoHoW project. R.J.S. is the principal investigator for the NoHoW trial. B.L.H. is the project coordinator, and S.E.S. and C.D. are the trial managers. S.C.L., A.L.P., S.E.S., and C.D. are site coordinators. G.H. is the trial statistician and leads data management. M.E., M.H., and E.M. are responsible for the technological development and management of the NoHoW digital TK. A.L.P., M.M.M., M.M., and C.D. developed the content of the arms of the digital TK. J.E., I.S., M.-L.M., S.C.L., C.S., B.P., and L.R. conducted the trial activities at each respective trial sites. E.H.E. and K.S. were involved in the development of some of the trial outcome measures. R.J.S. drafted this paper and all of the authors revised and approved the final version of this conceptual review.

\section{References}

1 World Health Organization. Obesity and overweight. 2020 [cited 2021 Feb 20]. Available from: https://www.who.int/news-room/ fact-sheets/detail/obesity-and-overweight.

2 World Health Organization. Global action plan for the prevention and control of noncommunicable diseases 2013-2020. 2013.

3 Branca F, Nikogosian H, Lobstein T; World Health Organization. The challenge of obesity in the WHO European region and the strategies for response. Copenhagen: WHO; 2007.

4 Wang YC, McPherson K, Marsh T, Gortmaker SL, Brown M. Health and economic burden of the projected obesity trends in the USA and the UK. Lancet. 2011 Aug;378(9793):815-25.

5 Yach D, Stuckler D, Brownell KD. Epidemiologic and economic consequences of the global epidemics of obesity and diabetes. Nat Med. 2006 Jan;12(1):62-6.

6 Finkelstein EA. The costs of obesity and implications for policymakers. Choices. 2010;25:1-7.

7 Müller-Riemenschneider F, Reinhold T, Berghöfer A, Willich SN. Health-economic burden of obesity in Europe. Eur J Epidemiol. 2008;23(8):499-509.

8 Swinburn BA, Sacks G, Hall KD, McPherson K, Finegood DT, Moodie ML, et al. The global obesity pandemic: shaped by global drivers and local environments. Lancet. 2011 Aug; 378(9793):804-14.

9 Gudzune KA, Doshi RS, Mehta AK, Chaudhry ZW, Jacobs DK, Vakil RM, et al. Efficacy of commercial weight-loss programs: an updated systematic review. Ann Intern Med. 2015 Apr;162(7):501-12.

10 Vakil RM, Chaudhry ZW, Doshi RS, Clark JM, Gudzune KA. Commercial Programs' Online Weight-Loss Claims Compared to Re- sults from Randomized Controlled Trials. Obesity (Silver Spring). 2017 Nov;25(11): 1885-93.

11 Santos I, Sniehotta FF, Marques MM, Carraça EV, Teixeira PJ. Prevalence of personal weight control attempts in adults: a systematic review and meta-analysis. Obes Rev. 2017 Jan;18(1): 32-50.

12 Wing RR, Phelan S. Long-term weight loss maintenance. Am J Clin Nutr. 2005 Jul;82(1 Suppl):222S-5S.

13 Stubbs RJ, Hopkins M, Finlayson GS, Duarte C, Gibbons C, Blundell JE. Potential effects of fat mass and fat-free mass on energy intake in different states of energy balance. Eur J Clin Nutr. 2018 May;72(5):698-709.

14 Sainsbury K, Evans EH, Pedersen S, Marques MM, Teixeira PJ, Lähteenmäki L, et al. Attribution of weight regain to emotional reasons amongst European adults with overweight and obesity who regained weight following a weight loss attempt. Eat Weight Disord. 2019 Apr;24(2):351-61.

15 Slater ME, Sirard JR, Laska MN, Pereira MA, Lytle LA. Relationships between energy balance knowledge and the home environment. J Am Diet Assoc. 2011 Apr;111(4):556-60.

16 Norris SL, Zhang X, Avenell A, Gregg E, Schmid CH, Lau J. Long-term non-pharmacological weight loss interventions for adults with prediabetes. Cochrane Database Syst Rev. 2005 Apr;(2):CD005270.

17 Franz MJ, VanWormer JJ, Crain AL, Boucher JL, Histon T, Caplan W, et al. Weight-loss outcomes: a systematic review and meta-analysis of weight-loss clinical trials with a minimum 1-year follow-up. J Am Diet Assoc. 2007 Oct;107(10):1755-67.
18 Anton SD, Han H, York E, Martin CK, Ravus$\sin$ E, Williamson DA. Effect of calorie restriction on subjective ratings of appetite. J Hum Nutr Diet. 2009 Apr;22(2):141-7.

19 Greaves CJ, Sheppard KE, Abraham C, Hardeman W, Roden M, Evans PH, et al.; IMAGE Study Group. Systematic review of reviews of intervention components associated with increased effectiveness in dietary and physical activity interventions. BMC Public Health. 2011 Feb;11(1):119.

20 Jolly K, Lewis A, Beach J, Denley J, Adab P, Deeks JJ, et al. Comparison of range of commercial or primary care led weight reduction programmes with minimal intervention control for weight loss in obesity: lighten Up randomised controlled trial. BMJ. 2011 Nov;343:d6500.

21 Leblanc ES, O'Connor E, Whitlock EP, Patnode CD, Kapka T. Effectiveness of primary care-relevant treatments for obesity in adults: a systematic evidence review for the U.S. Preventive Services Task Force. Ann Intern Med. 2011 Oct;155(7):434-47.

22 Kirk SF, Penney TL, McHugh TL, Sharma AM. Effective weight management practice: a review of the lifestyle intervention evidence. Int J Obes. 2012 Feb;36(2):178-85.

23 Gloy VL, Briel M, Bhatt DL, Kashyap SR, Schauer PR, Mingrone G, et al. Bariatric surgery versus non-surgical treatment for obesity: a systematic review and meta-analysis of randomised controlled trials. BMJ. 2013 Oct; 347:f5934.

24 Johnston BC, Kanters S, Bandayrel K, Wu P, Naji F, Siemieniuk RA, et al. Comparison of weight loss among named diet programs in overweight and obese adults: a meta-analysis. JAMA. 2014 Sep;312(9):923-33. 
25 Madigan CD, Daley AJ, Lewis AL, Jolly K, Aveyard P. Which weight-loss programmes are as effective as Weight Watchers $(\mathrm{R})$ ?: noninferiority analysis. Br J Gen Pract. 2014 Mar; 64(620):e128-36.

26 Khera R, Murad MH, Chandar AK, Dulai PS, Wang Z, Prokop LJ, et al. Association of pharmacological treatments for obesity with weight loss and adverse events: a systematic review and meta-analysis. JAMA. 2016 Jun; 315(22):2424-34.

27 Vakil RM, Doshi RS, Mehta AK, Chaudhry ZW, Jacobs DK, Lee CJ, et al. Direct comparisons of commercial weight-loss programs on weight, waist circumference, and blood pressure: a systematic review. BMC Public Health. 2016 Jun;16(1):460.

28 O'Brien PE, Hindle A, Brennan L, Skinner S, Burton P, Smith A, et al. Long-Term Outcomes After Bariatric Surgery: a Systematic Review and Meta-analysis of Weight Loss at 10 or More Years for All Bariatric Procedures and a Single-Centre Review of 20-Year Outcomes After Adjustable Gastric Banding. Obes Surg. 2019 Jan;29(1):3-14.

29 Douketis JD, Macie C, Thabane L, Williamson DF. Systematic review of long-term weight loss studies in obese adults: clinical significance and applicability to clinical practice. Int J Obes. 2005 Oct;29(10):1153-67.

30 Magro DO, Geloneze B, Delfini R, Pareja BC, Callejas F, Pareja JC. Long-term weight regain after gastric bypass: a 5-year prospective study. Obes Surg. 2008 Jun;18(6):648-51.

31 Loveman E, Frampton G, Shepherd J, Picot J, Cooper K, Bryant J, et al. The clinical effectiveness and cost-effectiveness of long-term weight management schemes for adults: a systematic review. Health Technol Assess. 2011 Jan;15(2):1-182.

32 Spring B, Champion KE, Acabchuk R, Hennessy EA. Self-regulatory behaviour change techniques in interventions to promote healthy eating, physical activity, or weight loss: a meta-review. Health Psychol Rev. 2020, Online ahead of print.

33 Glenny AM, O'Meara S, Melville A, Sheldon TA, Wilson C. The treatment and prevention of obesity: a systematic review of the literature. Int J Obes. 1995; 19:893-901.

34 Heshka S, Anderson JW, Atkinson RL, Greenway FL, Hill JO, Phinney SD, et al. Weight loss with self-help compared with a structured commercial program: a randomized trial. JAMA. 2003 Apr;289(14):1792-8.

35 Jebb SA, Ahern AL, Olson AD, Aston LM, Holzapfel C, Stoll J, et al. Primary care referral to a commercial provider for weight loss treatment versus standard care: a randomised controlled trial. Lancet. 2011 Oct;378(9801): 1485-92.

36 Stubbs RJ, Pallister C, Whybrow S, Avery A, Lavin JH. Weight outcomes for 34,271 participants in a commercial/primary care weight management partnership scheme. Obes Facts. 2011;4:113-20.
37 Stubbs RJ, Lavin JH. The challenges of implementing behaviour changes that lead to sustained weight management. Nutr Bull. 2013; 38(1):5-22.

38 Rössner S. Relapse Management. Int J Obes. 2008:31:S10.

39 Stubbs J, Whybrow S, Teixeira P, Blundell J, Lawton C, Westenhoefer J, et al. Problems in identifying predictors and correlates of weight loss and maintenance: implications for weight control therapies based on behaviour change. Obes Rev. 2011 Sep;12(9):688-708.

40 Thomas JG, Bond DS, Phelan S, Hill JO, Wing RR. Weight-loss maintenance for 10 years in the National Weight Control Registry. Am J Prev Med. 2014 Jan;46(1):17-23.

41 Vieira PN, Teixeira P, Sardinha LB, Santos T, Coutinho S, Mata J, et al. [Success in maintaining weight loss in Portugal: the Portuguese Weight Control Registry]. Cien Saude Colet. 2014 Jan;19(1):83-92.

42 Teixeira P. A systematic review of self-regulation mediators of success in obesity interventions: the SPOTLIGHT project. Obes Facts. 2013;6 Supplement 1:11.

43 Dombrowski S, Knittle K, Avenell A, AraujoSoares V, Sniehotta FF. Long-term maintenance of weight loss in obese adults: A systematic review of randomised controlled trials of nonsurgical weight loss maintenance interventions with meta-analyses. BMJ. 2014 May;348:g2646.

44 Varkevisser RD, van Stralen MM, Kroeze W, Ket JC, Steenhuis IH. Determinants of weight loss maintenance: a systematic review. Obes Rev. 2019 Feb;20(2):171-211.

45 Paixão C, Dias CM, Jorge R, Carraça EV, Yannakoulia M, de Zwaan M, et al. Successful weight loss maintenance: A systematic review of weight control registries. Obes Rev. 2020 May;21(5):e13003.

46 Sciamanna CN, Kiernan M, Rolls BJ, Boan J, Stuckey H, Kephart D, et al. Practices associated with weight loss versus weight-loss maintenance results of a national survey. Am J Prev Med. 2011 Aug;41(2):159-66.

47 Stubbs RJ, Duarte C, O'Driscoll R, Turicchi J, Michalowska J. Developing evidence-based behavioural strategies to overcome physiological resistance to weight loss in the general population. Proc Nutr Soc. 2019 Nov;78(4): 576-89.

48 Brownell KD, Marlatt GA, Lichtenstein E, Wilson GT. Understanding and preventing relapse. Am Psychol. 1986 Jul;41(7):765-82.

49 Heilbronn LK, de Jonge L, Frisard MI, DeLany JP, Larson-Meyer DE, Rood J, et al.; Pennington CALERIE Team. Effect of 6-month calorie restriction on biomarkers of longevity, metabolic adaptation, and oxidative stress in overweight individuals: a randomized controlled trial. JAMA. 2006 Apr;295(13):1539-48.

50 Martin CK, Heilbronn LK, de Jonge L, DeLany JP, Volaufova J, Anton SD, et al. Effect of calorie restriction on resting metabolic rate and spontaneous physical activity. Obesity (Silver Spring). 2007 Dec;15(12):2964-73.
51 Hall KD, Jordan PN. Modeling weight-loss maintenance to help prevent body weight regain. Am J Clin Nutr. 2008 Dec;88(6):1495503.

52 Lebel JL, Lu J, Dubé L. Weakened biological signals: highly-developed eating schemas amongst women are associated with maladaptive patterns of comfort food consumption. Physiol Behav. 2008 Jun;94(3):384-92.

53 Bosy-Westphal A, Kossel E, Goele K, Later W, Hitze B, Settler U, et al. Contribution of individual organ mass loss to weight loss-associated decline in resting energy expenditure. Am J Clin Nutr. 2009 Oct;90(4):993-1001.

54 Hall KD. Modeling metabolic adaptations and energy regulation in humans. Annu Rev Nutr. 2012 Aug;32(1):35-54.

55 Maes S, Karoly P. Self-Regulation Assessment and Intervention in Physical Health and Illness: A Review. Appl Psychol. 2005;54(2): 267-99.

56 Sniehotta FF, Schwarzer R, Scholz U, Schüz B. Action planning and coping planning for long-term lifestyle change: theory and assessment. Eur J Soc Psychol. 2005;35(4):565-76.

57 Sniehotta FF, Scholz U, Schwarzer R. Bridging the intention-behaviour gap: Planning, self-efficacy, and action control in the adoption and maintenance of physical exercise. Psychol Health. 2005;20(2):143-60.

58 Dombrowski SU, Avenell A, Sniehott FF. Behavioural interventions for obese adults with additional risk factors for morbidity: systematic review of effects on behaviour, weight and disease risk factors. Obes Facts. 2010 Dec; 3(6):377-96.

59 Teixeira PJ, Mata J, Williams GC, Gorin AA, Lemieux S. Self-regulation, motivation, and psychosocial factors in weight management. J Obes. 2012;2012:582348.

60 Larimer ME, Palmer RS, Marlatt GA. Relapse prevention. An overview of Marlatt's cognitive-behavioral model. Alcohol Res Health. 1999;23(2):151-60.

61 Silva MN, Markland D, Carraça EV, Vieira PN, Coutinho SR, Minderico CS, et al. Exercise autonomous motivation predicts 3 -yr weight loss in women. Med Sci Sports Exerc. 2011 Apr;43(4):728-37.

62 Teixeira PJ, Silva MN, Mata J, Palmeira AL, Markland D. Motivation, self-determination, and long-term weight control. Int J Behav Nutr Phys Act. 2012 Mar;9(1):22.

63 Teixeira PJ, Carraça EV, Marques MM, Rutter H, Oppert JM, De Bourdeaudhuij I, et al. Successful behavior change in obesity interventions in adults: a systematic review of self-regulation mediators. BMC Med. 2015 Apr; 13(1):84.

64 Samdal GB, Eide GE, Barth T, Williams G, Meland E. Effective behaviour change techniques for physical activity and healthy eating in overweight and obese adults; systematic review and meta-regression analyses. Int $\mathrm{J} \mathrm{Be}-$ hav Nutr Phys Act. 2017 Mar;14(1):42. 
65 Hennessy EA, Johnson BT, Acabchuk RL, McCloskey K, Stewart-James J. Self-regulation mechanisms in health behavior change: a systematic meta-review of meta-analyses, 2006-2017. Health Psychol Rev. 2020 Mar; 14(1):6-42.

66 Carey RN, Connell LE, Johnston M, Rothman AJ, de Bruin M, Kelly MP, et al. Behavior change techniques and their mechanisms of action: a synthesis of links described in published intervention literature. Ann Behav Med. 2019 Jul;53(8):693-707.

67 Connell LE, Carey RN, de Bruin M, Rothman AJ, Johnston M, Kelly MP, et al. Links between behavior change techniques and mechanisms of action: an expert consensus study. Ann Behav Med. 2019 Jul;53(8):708-20.

68 Armitage CJ, Conner M. Social cognition models and health behaviour: A structured review. Psychol Health. 2000;15(2):173-89.

69 Sniehotta FF. Towards a theory of intentional behaviour change: plans, planning, and selfregulation. Br J Health Psychol. 2009 May; 14(Pt 2):261-73.

70 Gibbons FX, Houlihan AE, Gerrard M. Reason and reaction: the utility of a dual-focus, dual-processing perspective on promotion and prevention of adolescent health risk behaviour. Br J Health Psychol. 2009 May; 14(Pt 2):231-48.

71 Hofmann W, Friese M, Strack F. Impulse and self-control from a dual-systems perspective. Perspect Psychol Sci. 2009 Mar;4(2):162-76.

72 Bargh JA, Chartrand TL. The unbearable automaticity of being. Am Psychol. 1999;54(7): $462-79$.

73 Rebar AL, Dimmock JA, Jackson B, Rhodes RE, Kates A, Starling J, et al. A systematic review of the effects of non-conscious regulatory processes in physical activity. Health Psychol Rev. 2016 Dec;10(4):395-407.

74 Gardner B, Rebar AL, Lally P. A matter of habit: recognizing the multiple roles of habit in health behaviour. Br J Health Psychol. 2019 May;24(2):241-9.

75 Finlayson G, King N, Blundell JE. Liking vs. wanting food: importance for human appetite control and weight regulation. Neurosci Biobehav Rev. 2007;31(7):987-1002.

76 Finlayson G, King N, Blundell J. The role of implicit wanting in relation to explicit liking and wanting for food: implications for appetite control. Appetite. 2008 Jan;50(1):120-7.

77 Lemmens SG, Rutters F, Born JM, Westerterp-Plantenga MS. Stress augments food 'wanting' and energy intake in visceral overweight subjects in the absence of hunger. Physiol Behav. 2011 May; 103(2):157-63.

78 Stubbs RJ, Gail C, Whybrow S, Gilbert P. The evolutionary inevitability of obesity in modern society: implications for behavioral solutions to weight control in the general population. In: Martinez MP, Robinson $\mathrm{H}$, editors. Obesity and weight management: challenges, practices and health implications: public health in the 21st century, nutrition and diet research progress. Edinburgh: Novo; 2012.
79 Latner JD, O’Brien KS, Durso LE, Brinkman LA, MacDonald T. Weighing obesity stigma: the relative strength of different forms of bias. Int J Obes. 2008 Jul;32(7):1145-52.

80 Puhl RM, Heuer CA. The stigma of obesity: a review and update. Obesity (Silver Spring). 2009 May; 17(5):941-64.

81 Schafer MH, Ferraro KF. The Stigma of Obesity: Does Weight Discrimination Affect Identity and Physical Health? Soc Psychol Q. 2011;74(1):76-97.

82 Ferreira C, Pinto-Gouveia J, Duarte C. Physical appearance as a measure of social ranking: the role of a new scale to understand the relationship between weight and dieting. Clin Psychol Psychother. 2013 Jan-Feb;20(1):55-66.

83 Gilbert P. Body shame: A biopsychosocial conceptualisation and overview, with treatment implications. In: Gilbert P, Miles J, editors. Body shame: Conceptualisation, research and treatment. London: Brunner; 2002. p. 3-54

84 Matos M, Ferreira C, Duarte C, Pinto-Gouveia J. Eating disorders: when social rank perceptions are shaped by early shame experiences. Psychol Psychother. 2015 Mar;88(1): 38-53.

85 Jambekar SA, Masheb RM, Grilo CM. Gender differences in shame in patients with bingeeating disorder. Obes Res. 2003 Apr;11(4): 571-7.

86 Gee A, Troop NA. Shame, depressive symptoms and eating, weight and shape concerns in a non-clinical sample. Eat Weight Disord. 2003 Mar;8(1):72-5.

87 Fennig S, Hadas A, Itzhaky L, Roe D, Apter A, Shahar G. Self-criticism is a key predictor of eating disorder dimensions among inpatient adolescent females. Int J Eat Disord. 2008 Dec;41(8):762-5.

88 Gilbert $\mathrm{P}$. The origins and nature of compassion focused therapy. Br J Clin Psychol. 2014 Mar;53(1):6-41.

89 O'Reilly GA, Cook L, Spruijt-Metz D, Black DS. Mindfulness-based interventions for obesity-related eating behaviours: a literature review. Obes Rev. 2014 Jun;15(6):453-61.

90 Forman EM, Butryn ML. A new look at the science of weight control: how acceptance and commitment strategies can address the challenge of self-regulation. Appetite. 2015 Jan; 84:171-80.

91 Hayes SC, Luoma JB, Bond FW, Masuda A, Lillis J. Acceptance and commitment therapy: model, processes and outcomes. Behav Res Ther. 2006 Jan; 44(1):1-25.

92 Forman EM, Butryn ML, Hoffman KL, Herbert JD. An Open Trial of an AcceptanceBased Behavioral Intervention for Weight Loss. Cognit Behav Pract. 2008;16(2):223-35.

93 Puhl RM, Heuer CA. Obesity stigma: important considerations for public health. Am J Public Health. 2010 Jun;100(6):1019-28.
94 Hayes SC, Strosahl KD, Wilson KG. Acceptance and commitment therapy: The process and practice of mindful change. 2 nd ed. New York: Guilford Press; 2011.

95 Niemeier HM, Leahey T, Palm Reed K, Brown RA, Wing RR. An acceptance-based behavioral intervention for weight loss: a pilot study. Behav Ther. 2012 Jun;43(2):42735.

96 Ferreira C, Pinto-Gouveia J, Duarte C. Selfcompassion in the face of shame and body image dissatisfaction: implications for eating disorders. Eat Behav. 2013 Apr;14(2): $207-10$.

97 Forman EM, Butryn ML, Juarascio AS, Bradley LE, Lowe MR, Herbert JD, et al. The mind your health project: a randomized controlled trial of an innovative behavioral treatment for obesity. Obesity (Silver Spring). 2013 Jun;21(6):1119-26.

98 Teixeira PJ, Going SB, Houtkooper LB, Cussler EC, Metcalfe LL, Blew RM, et al. Pretreatment predictors of attrition and successful weight management in women. Int J Obes Relat Metab Disord. 2004 Sep; 28(9):1124-33.

99 Carraça EV, Santos I, Mata J, Teixeira PJ. Psychosocial Pretreatment Predictors of Weight Control: A Systematic Review Update. Obes Facts. 2018;11(1):67-82.

100 Breton ER, Fuemmeler BF, Abroms LC. Weight loss-there is an app for that! But does it adhere to evidence-informed practices? Transl Behav Med. 2011 Dec;1(4): 523-9.

101 Pagoto S, Schneider K, Jojic M, DeBiasse M, Mann D. Evidence-based strategies in weight-loss mobile apps. Am J Prev Med. 2013 Nov;45(5):576-82.

102 Schoeppe S, Alley S, Van Lippevelde W, Bray NA, Williams SL, Duncan MJ, et al. Efficacy of interventions that use apps to improve diet, physical activity and sedentary behaviour: a systematic review. Int J Behav Nutr Phys Act. 2016 Dec;13(1):127.

103 Hutchesson MJ, Rollo ME, Krukowski R, Ells L, Harvey J, Morgan PJ, et al. eHealth interventions for the prevention and treatment of overweight and obesity in adults: a systematic review with meta-analysis. Obes Rev. 2015 May; 16(5):376-92.

104 Villinger K, Wahl DR, Boeing H, Schupp HT, Renner B. The effectiveness of appbased mobile interventions on nutrition behaviours and nutrition-related health outcomes: A systematic review and meta-analysis. Obes Rev. 2019 Oct;20(10):1465-84.

105 Bardus M, Smith JR, Samaha L, Abraham C. Mobile and Web 2.0 interventions for weight management: an overview of review evidence and its methodological quality. Eur J Public Health. 2016 Aug;26(4):60210.

106 Dounavi K, Tsoumani O. Mobile health applications in weight management: a systematic literature review. Am J Prev Med. 2019 Jun;56(6):894-903. 
107 Evans EH, Sainsbury K, Marques MM, Santos I, Pedersen S, Lähteenmäki L, et al. Prevalence and predictors of weight loss maintenance: a retrospective population-based survey of European adults with overweight and obesity. J Hum Nutr Diet. 2019 Dec; 32(6):745-53.

108 Brown J, Kotz D, Michie S, Stapleton J, Walmsley M, West R. How effective and cost-effective was the national mass media smoking cessation campaign 'Stoptober'? Drug Alcohol Depend. 2014 Feb;135:52-8.

109 Wright P, Blythw MA. Pastiche scenarios: fiction as a resource for user centred design. Interact Comput. 2006;18:1139-64.

110 Wright P, Wallace J, McCarthy J. Aesthetics and experience-centered design. ACM Trans Comput Hum Interact. 2008. doi: 10.1145/1460355.1460360.

111 Wright P. Experience-centered design: Designers, users, and communities in dialogue (synthesis lectures on human-centered informatics). Williston: Morgan and Claypool; 2010. p. 1-123.

112 Scott SE, Duarte C, Encantado J, Evans EH, Harjumaa M, Heitmann BL, et al. The NoHoW protocol: a multicentre $2 \times 2$ factorial randomised controlled trial investigating an evidence-based digital toolkit for weight loss maintenance in European adults. BMJ Open. 2019 Sep;9(9):e029425.
113 O’Driscoll R, Turicchi J, Hopkins M, Gibbons C, Larsen SC, Palmeira AL, et al. The validity of two widely used commercial and research-grade activity monitors, during resting, household and activity behaviours. Health Technol. 2019;10:637-48.

114 Larsen SC, Horgan G, Mikkelsen MK, Palmeira AL, Scott S, Duarte C, et al. Association between objectively measured sleep duration, adiposity and weight loss history. Int J Obes. 2020 Jul;44(7):1577-85.

115 Stubbs RJ, Morris L, Pallister C, Horgan G, Lavin JH. Weight outcomes audit in 1.3 million adults during their first 3 months' attendance in a commercial weight management programme. BMC Public Health. 2015 Sep;15(1):882.

116 Pedersen S, Sniehotta FF, Sainsbury K, Evans EH, Marques MM, Stubbs RJ, et al. The complexity of self-regulating food intake in weight loss maintenance. A qualitative study among short- and long-term weight loss maintainers. Soc Sci Med. 2018 Jul;208: 18-24.

117 Ahtinen A, Mattila E, Välkkynen P, Kaipainen KV, Toni; Ermes M, Sairanen E, et al. Mobile Mental Wellness Training for Stress Management: Feasibility and Design Implications Based on a One-Month Field Study. JMIR Mhealth Uhealth. 2013 Jul; 1(2):e11.

118 O’Driscoll R, Turicchi J, Hopkins M, Horgan GW, Finlayson G, Stubbs JR. Improving energy expenditure estimates from wearable devices: A machine learning approach. J Sports Sci. 2020 Jul;38(13):1496-505.
119 Dombrowski SU, Sniehotta FF, Avenell A, Johnston M, MacLennan G, Araújo-Soares V. V A-S. Identifying active ingredients in complex behavioural interventions for obese adults with obesity-related co-morbidities or additional risk factors for comorbidities: a systematic review. Health Psychol Rev. 2012;6(1):7-32.

120 Kwasnicka D, Presseau J, White M, Sniehotta FF. Does planning how to cope with anticipated barriers facilitate health-related behavior change? A systematic review. Health Psychol Rev. 2013;7(2):129-45.

121 Kwasnicka D, Dombrowski SU, White M, Sniehotta F. Theoretical explanations for maintenance of behaviour change: a systematic review of behaviour theories. Health Psychol Rev. 2016 Sep;10(3):277-96.

122 Hall KD. Estimating human energy intake using mathematical models. Am J Clin Nutr. 2014 Sep;100(3):744-5.

123 Sanghvi A, Redman LM, Martin CK, Ravus$\sin \mathrm{E}$, Hall KD. Validation of an inexpensive and accurate mathematical method to measure long-term changes in free-living energy intake. Am J Clin Nutr. 2015 Aug;102(2): 353-8.

124 European Commission. eHealth Action Plan 2012-2020: Innovative healthcare for the 21st century. 2012. Available from: http://ec.europa.eu/digital-agenda/en/ news/ehealth-action-plan-2012-2020-innovative-healthcare-21st-century. 